Brit. F. vener. Dis. (1969), 45, 6.

\title{
A NEW MODIFICATION OF THE KRAJIAN SILVER STAIN FOR Treponema pallidum*
}

\author{
BY \\ ELEANOR K. WALTER, J. LAWTON SMITH, \\ CHARLES W. ISRAEL $\dagger$, AND WALTER E. GAGER $\ddagger$ \\ From the Department of Ophthalmology, University of Miami School of Medicine, Miami, Florida 33136
}

The need for a consistently reliable silver stain for Treponema pallidum in paraffin sections made us aware that further investigation of the technique was needed. Three methods were tried and discarded:

(1) The Levaditi stain, which was originally planned for use in staining entire blocks of tissue fixed in 10 per cent. formalin. After the staining is completed, the stained tissue block is embedded in paraffin and sectioned. This method was found to be extremely time-consuming; 3 to 5 days were required for the silver nitrate impregnation alone, and another 27 to 72 hours for the silver reduction. Numerous attempts were made to adapt this technique for use with single paraffin sections without success.

(2) The Steiner and Steiner (1944) stain for spirochaetes and Donovan bodies gave some positive results with control material. However, it was timeconsuming, and the results obtained were not consistent.

(3) The Dieterle stain for spirochaetes produced only fair results. The staining procedure was quite lengthy and this precluded its use in a laboratory performing a large number of silver stains.

A modification of the Krajian silver impregnation technique (Krajian, 1939; Krajian and Gradwohl, 1952) developed by Miss Janice Bullard at the Venereal Disease Research Laboratory in Atlanta, Georgia, was brought to our attention. Although stains of good quality were obtained with this method, they would frequently fade within hours.

\footnotetext{
* Received for publication July 22, 1968.

† Special Fellowship 2-F11-NB-1633-02 VSN, National Institute of Neurological Diseases and Blindness.

†Special Fellowship 1-F11-NB-1792-01 VSN, National Institute of Neurological Diseases and Blindness.

This work supported in part by grants 5 RO 1 CC 00144-03, Communicable Disease Center; 5 RO 1 NB 06308-02, NB-05277-08, and 1 RO 1 NB 06574-02, National Institute of Neurological Diseases and Blindness.
}

Thus, stains initially of good quality were impossible to read the following day.

In an attempt to correct this fading and because an analogous situation seemed to exist between the processing of photographic film and the reduction of the impregnated colloidal silver in the tissue section, the fixative used in photographic processing, sodium thiosulphate, was inserted as an additional step. This technique has been used for over 3 years with consistently good results, an example of which is shown in the Figure. The Krajian stain has the advantage of being rapid (five slides can be stained in one hour) and, most important, it has proved to be the most reliable method in our hands to date.

The purpose of this report is to describe in detail the exact equipment used and procedure involved in our modification of the Krajian stain.

\section{Material and Methods}

\section{A. Glassware}

All glassware used in this procedure must be acid clean.* The 125-ml. flasks and Coplin jars used for the developer are rinsed in 95 per cent. alcohol to remove any gum mastic and then soaked in cleaning solution after each set of slides. Several such flasks and Coplin jars should be available to avoid delay if several sets of slides are to be stained in one day. The $100-\mathrm{ml}$. beakers used for the 1 per cent. silver nitrate can be rinsed with distilled water and used a second time before being cleaned. The necessary glassware should be used solely for this staining procedure. Vertical staining jars may be used for all solutions. As a point of economy, the developer and the sodium thiosulphate solutions are placed in Coplin jars. We recommend that the glassware be labelled so that each jar used contains the same solution each time the stain is performed.

\footnotetext{
^Acid cleaning solution: Potassium dichromate $160 \mathrm{~g}$.
Water
$2,000 \mathrm{ml}$. Water
Sulphuric acid
} 


\section{B. Apparatus Needed}

(1) One dozen vertical staining jars

(2) One dozen Coplin jars

(3) Six 125-ml. Erlenmeyer flasks, Pyrex

(4) Six 100-ml. beakers, Pyrex

(5) One tripod

(6) One wire gauge

(7) One Fisher burner

(8) One gooseneck type desk lamp

(9) One water bath adjusted to $60^{\circ} \mathrm{C}$.

(10) One pair slide forceps

(11) Plastic slide holdert

(12) One dozen 5-ml. pipettes

(13) Pipette filler Propipetteł (for use with Pyridine)

(14) One 30-ml. graduated cylinder

(15) One glass-stoppered 100-ml. graduated cylinder

\section{Reagents}

(1) Triple distilled water

(2) Xylol

(3) Absolute ethanol

(4) 95 per cent. ethanol

(5) Number One Solution (Mordant solution)

$\begin{array}{lr}\text { Uranium nitrate } & 2 \mathrm{~g} . \\ \text { Formic acid } & 6 \mathrm{ml} . \\ \text { Glycerine } & 10 \mathrm{ml} \text {. } \\ \text { Acetone } & 20 \mathrm{ml} \text {. } \\ \text { 95 per cent. alcohol } & 20 \mathrm{ml} \text {. }\end{array}$

This solution may be made up in larger quantities if frequent silver staining is performed. The solution keeps well for up to 6 months if stored in a brown glass container and kept away from light. An appropriate amount of this solution is preheated in a water bath at $60^{\circ} \mathrm{C}$. each day that silver staining is to be done. Discard after each day's use.

\section{(6) Saturated Gum Mastic}

This solution may be prepared in any quantity desired utilizing a ratio of $1 \mathrm{~g}$. gum mastic to $1.4 \mathrm{ml}$. absolute ethanol. The gum mastic should be made up several days before it is to be used. Shake frequently and filter through several layers of gauze into a clean bottle. Use only the clear filtrate. The solution will keep indefinitely.

\section{(7) Dilute Gum Mastic}

This is prepared fresh each day by placing 70 drops of saturated gum mastic solution into $100 \mathrm{ml}$. 95 per cent. alcohol. After one day's use, the solution is discarded.

\section{(8) 1 per cent. Silver Nitrate}

This solution is used only once. If frequent silver staining is done, a stock solution of $100 \mathrm{ml}$. 10 per cent. silver nitrate may be kept in a brown bottle in the

tThe slide holder used is a Peel-A-Way Plastic Slide Grip Model SG-5. These are manufactured by Peel-A-Way Scientific and are distributed by W. Glenn Wunderly Company, 232 North Lake Avenue, Pasadena, California 91101.

$\ddagger$ Pipette filler, Propipette. Obtained from Scientific Products, Division of American Hospital Supply Corporation, 1210 Leon Place, Evanston, Illinois 60201, Catalogue No. P-5310. refrigerator. This quantity is sufficient for staining approximately ten sets of slides. The stock solution will keep for about one week. Old silver nitrate stock solution should never be used.

$\begin{array}{ll}\text { (9) Developer } & \\ \text { Hydroquinone } & 0.62 \mathrm{~g} . \\ \text { Sodium sulphite } & 0.2 \mathrm{~g} . \\ \text { Formaldehyde (40 per cent.) } & 5 \mathrm{ml} \text {. } \\ \text { Acetone } & 5 \mathrm{ml} \text {. } \\ \text { Pyridine (use Propipette to transfer fluid) } & 5 \mathrm{ml} . \\ \text { Saturated gum mastic } & 5 \mathrm{ml} . \\ \text { Distilled water } & 30 \mathrm{ml} .\end{array}$

The first two ingredients are weighed out and placed in a $125-\mathrm{ml}$. Erlenmeyer flask before beginning the staining procedure. The liquid ingredients are not combined at this time. The slides being stained are placed in 1 per cent. silver nitrate for 7 minutes. When 4 minutes of this immersion period remain, the final preparation of the developer is begun (see Step 9 of Staining Procedure). The liquid ingredients are pipetted into the previously weighed hydroquinone and sodium sulphite in the order listed. The developer is then heated to approximately $60^{\circ} \mathrm{C}$. by rotating the handheld 125-ml. Pyrex flask over an open flame. At the end of the 7-minute silver nitrate immersion period, the heated developer is transferred into a Coplin jar. Fresh developer solution must be prepared for each set of slides.

\section{(10) Sodium Thiosulphate 5 per cent. Aqueous Solution}

\section{Staining Procedure}

(1) Fix tissue in 10 per cent. formalin for a minimum of 12 to 24 hours.

(2) Dehydrate specimen: 70 per cent. alcohol, 95 per cent. alcohol, absolute alcohol (two changes), chloroform (two changes).

(3) Embed tissue in paraffin.

(4) Cut paraffin sections at 5 microns thickness.

(5) Stain five slides at a time (one positive control and four unknowns).

(6) Deparaffinize sections: xylol, absolute alcohol, 95 per cent. alcohol, water.

(7) Heat $75 \mathrm{ml}$. Number One Solution in a vertical staining jar to $60^{\circ} \mathrm{C}$. in a water bath. This solution is discarded after one day's use.

(8) Immerse slides in preheated Number One Solution for 10 minutes. Keep vertical staining jar containing Number One Solution and slides in $60^{\circ} \mathrm{C}$. water bath during this time in order to maintain temperature.

(9) Remove slides from Number One Solution and rinse in distilled water.

(10) Place slides one at a time in dilute gum mastic for 5 seconds. 


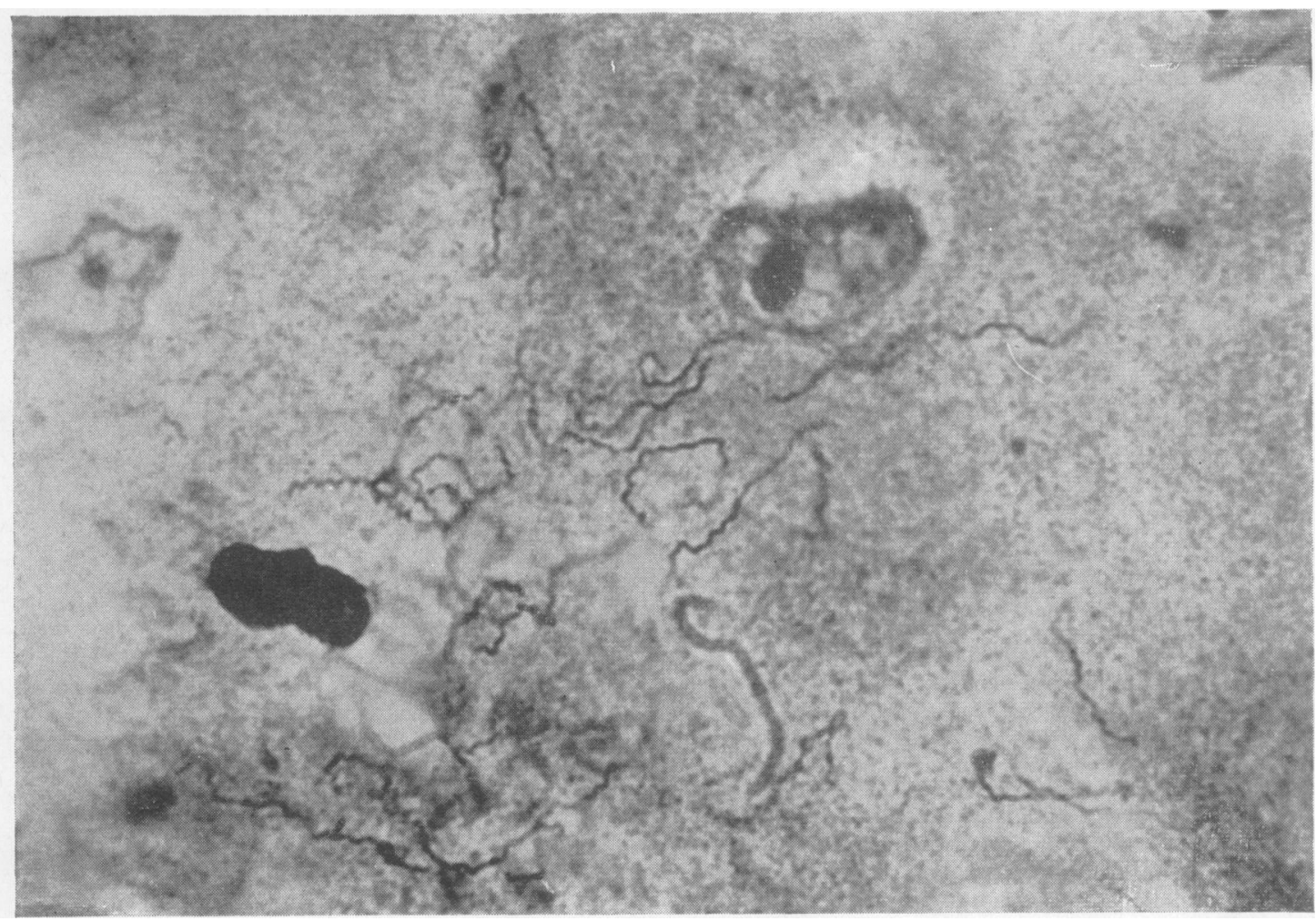

FIGURE.-Treponema pallidum stained with the modified Krajian silver stain.

(11) Wash well in distilled water. Drain the slides on a paper towel.

(12) Place the slides in the Peel-A-Way plastic slide-grip holder. Immerse the slides for 7 minutes in a $100-\mathrm{ml}$. beaker containing 1 per cent. silver nitrate pre-heated to $70-75^{\circ} \mathrm{C}$. A low Fisher burner flame is used to maintain this temperature. If the temperature drops below $70^{\circ} \mathrm{C}$. when the slides are placed in the solution, do not begin the seven-minute time interval until it returns to $70^{\circ} \mathrm{C}$.

(13) When 4 minutes of the 7-minute silver nitrate immersion period remain, the final preparation of the developer solution is begun. The liquid ingredients are pipetted into the previously weighed hydroquinone and sodium sulphite. The developer is then heated to approximately $60^{\circ} \mathrm{C}$. Simultaneously with the completion of the seven-minute silver nitrate time interval, the heated developer is transferred into a Coplin jar.

(14) Remove the slides from the 1 per cent. silver nitrate solution. Dip the slides-still in the plastic slide-grip holder-directly into the
Coplin jar containing the developer. The slides are dipped into the developer for 3-5 seconds and then withdrawn and held close (1-2 inches) to a 60-watt tungsten light source for 10-15 seconds. Repeat this dipping and exposure to light five to seven times until the sections are a medium brown or dark yellow colour.

(15) Wash sections - still in the holder-by dipping five or six times in 95 per cent. alcohol to dissolve gum mastic which sticks to the slides.

(16) Wash sections in distilled water.

(17) Return the slides to the 1 per cent. silver nitrate solution for thirty seconds. Time this step.

(18) Wash the slides in distilled water.

(19) Place holder with slides in 5 per cent. aqueous solution of sodium thiosulphate for 5 minutes.

(20) Rinse slides in distilled water for 1 minute.

(21) Dehydrate sections through 95 per cent. alcohol and two changes of absolute alcohol. Place sections in each solution for approximately 30 seconds. 
(22) Immerse sections in xylol until clearing occurs (15-30 seconds). The slides should then be mounted in Permount. The sections should not be allowed to remain in the xylol for a prolonged period of time, since it has been our experience that xylol causes fading of the impregnated reduced silver if the sections remain in contact with the solution for as little as 15 minutes.

\section{Summary}

A modification of the Krajian silver stain for Treponema pallidum has been presented. This method has provided consistently good silver impregnation of Treponema pallidum in paraffin sections and should be of definite value in any laboratory where silver stains for the histologic demonstration of this organism are performed frequently.

\section{REFERENCES}

Krajian, A. A. (1939). Amer. F. Syph., 23, 617.
Krajian, A. A., and Gradwohl, R. B. H. (1952). "Histopathological Technic", 2nd ed. Mosby, St. Louis.

STEINER, G., and STEINER, G. (1944). F. Lab. clin. Med., 29,868 .

\section{ADDITIONAL BIBLIOGRAPHY}

KerR, D. A. (1938). Amer. F. clin. Path., 8, Tech. Suppl., vol. 2, p. 63.

MalloRY, F. B. (1938). "Pathological Technique", p. 293. Saunders, Philadelphia.

Une nouvelle modification du colorant argenté Krajian pour le Treponema pallidum

\section{RÉSUMÉ}

Une modification du colorant argenté Krajian pour démontrer le Treponema pallidum a été présentée. Cette méthode a procuré d'une façon régulière une bonne imprégnation d'argent le Treponema pallidum dans les coupes à la paraffine solide et devrait être d'une valeur bien déterminée dans n'importe quel laboratoire où les colorants argentés sont employés fréquemment pour la démonstration histologique de cet organisme. 